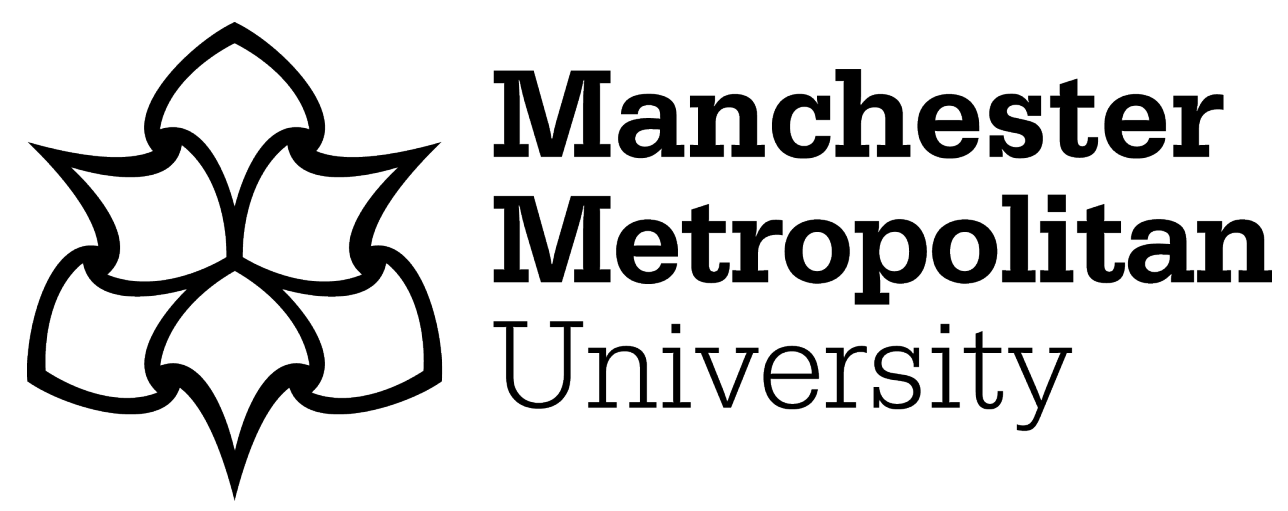

Hagan, Robert ORCID logoORCID: https://orcid.org/0000-0003-1184-229X, Manktelow, Roger and Taylor, Brian (2020) Loneliness, cumulative inequality and social capital in later life: Two stories. Irish Journal of Sociology, 28 (2). pp. 192-217. ISSN 0791-6035

Downloaded from: https://e-space.mmu.ac.uk/625301/

Version: Accepted Version

Publisher: SAGE Publications

DOI: https://doi.org/10.1177/0791603520908764

Please cite the published version 


\title{
Loneliness, cumulative inequality and social capital in later life: Two stories
}

\begin{abstract}
The potential impact of cumulative inequality upon loneliness in later life is under-researched. This study applies Ferraro \& Shippee's (2009) axioms of cumulative inequality to the narratives of two Northern Irish older women, who completed semi-structured diary entries over a 16-week period, recording and reflecting on their social lives and their personal histories. The two women were subsequently interviewed on the basis of what they had recorded. These stories reveal how the life trajectories of these two individuals are influenced by the different experiential impact of bonding and bridging social capital. Despite similar life experiences, significant and substantial differences emerged in the women's stories, relating to work life, social class, the restrictions of a caring role, and physical and mental health. These two narratives not only provide evidence of the impact of cumulative inequality on loneliness but also highlight the lifetime impact of socio-economic status and access to capital affecting older women's vulnerability to loneliness.
\end{abstract}

\section{Keywords}

Loneliness, cumulative inequality, social capital, life course review, narrative enquiry, diaries 


\section{What is known}

- Loneliness is a pertinent issue for a minority of older people

- Later life transitions such as increasing age, beginning to live alone, bereavement and health and mobility impairments are associated with loneliness in later life

- Social group interventions can be effective at tackling loneliness

\section{What this paper adds}

- Cumulative inequality and access to social capital mediate experiences of loneliness in later life

- Therefore, when considering the impact of loneliness, ecological factors from much earlier in the life course must be considered alongside those directly related to the person

- Personal insights into loneliness using the diary/diary interview approach 


\section{Background}

Approximately one in ten older people in the UK report being often or always lonely (Victor \& Bowling, 2012). Loneliness is a subjective experience, with psychosocial literature identifying that loneliness does not relate to the quantity of contact with others but rather to a cognitive discrepancy between one's desired level of connection and that which is actually experienced (Heinrich \& Gullone, 2006). Additionally, certain relationships, such as those with spouses or very close family and friends, are particularly valuable for a sense of belongingness (Baumeister \& Leary, 1995), and deficits in these is not easily rectified merely by increased social contact with others (Russell, Cutrona, McRae \& Gomez, 2012). In later life, loneliness is associated with living alone (De Jong Gierveld, Dykstra \& Shenk, 2012), bereavement (Fried et al., 2015), increasing age and longevity (Dykstra, Van Tilburg \& De Jong Gierveld, 2005), poor physical health (Burholt \& Scharf, 2014) and dissatisfaction with social contacts (Rodrigues, De Jong Gierveld \& Buz, 2013). These factors alone do not fully explain experiences of loneliness in later life as all these appear in the narratives of two older women presented below to varying degrees. What this article argues is that experiences of cumulative inequality and weaker access to bridging social capital mediate felt loneliness.

The purpose of this piece is to consider how cumulative inequality has amplified disadvantage in one woman and protected another. For this paper, two stories have been extracted from a larger qualitative sample due to similarities that offer the opportunity for comparison and contrast, particularly in relationship to social class differences. Background information on the two storytellers is presented in Table 1.

Table 1: Background information on the storytellers

\begin{tabular}{lll}
\hline & Amber & Rochelle \\
\hline Age & 68 & 85 \\
Marital status & Widow (less than one year) & Widow (less than one year)
\end{tabular}


Children

\begin{tabular}{|c|c|c|}
\hline & with brain injury) & one with head injury) \\
\hline Living arrangement & With adult son & Living on own \\
\hline Location/type of home & $\begin{array}{l}\text { Suburban terraced (social } \\
\text { housing estate) }\end{array}$ & Rural detached \\
\hline Home status & Owned & Owned \\
\hline Faith adherence & Catholic & Protestant (Presbyterian) \\
\hline $\begin{array}{l}\text { Loneliness score } \\
\qquad \text { (De Jong Gierveld*) }\end{array}$ & 8 & 2 \\
\hline
\end{tabular}

The first respondent, Amber, is from a Catholic working class background and lives on a social housing estate, whilst the second, Rochelle, is a Protestant middle class retired professional, who lives rurally in a detached dwelling with substantial grounds. The lead researcher met both women when they attended a local day centre for the first time: this is a statutory service providing socialising opportunities and therapeutic activities for older people who live independently (Caiels et al., 2010; Gaugler \& Zarit, 2001). These participants were primarily referred to attend specific therapeutic programming on mental health, physical health and improving mobility. At time of referral, both women had been widowed for less than one year and both had sons who sustained traumatic head injuries in adulthood. Despite these commonalities, there were striking differences in terms of living arrangement and experience of loneliness. Using De Jong Gierveld and van Tilburg's (1999) 11-item loneliness scale, where a score of three indicates moderate loneliness, Amber's score of eight is close to feeling severely lonely whilst Rochelle's score of two corresponds to not being lonely. The involvement of both women in day centre programmes, to which they were referred by health and social care professionals on the basis of concerns related to health and well-being, comprise the 'endpoints' of the stories. What this article is particularly interested in is the arc within the individuals' lives that has led to this point and to their contemporaneous assessments of loneliness. The following subsections present the key theories that help inform this. 


\section{Cumulative Inequality}

Cumulative inequality describes the ongoing impact throughout the life course of being exposed to poorer material circumstances, leading to both direct and indirect effects on individuals' well-being (Ferraro \& Shippee, 2009; Dannefer, 2003). The model builds on Dannefer's earlier theorising on cumulative advantage and disadvantage by explicitly relating life course theory to produce a series of axioms that can be applied to older people's situations (Ferraro \& Shippee, 2009). These are outlined in Table 2. Aspects of inequality throughout the life course include access to housing, diet, job opportunities and educational pathways. Deficits in these areas have an accumulating effect that amplifies disadvantage (Dannefer \& Settersen, 2010). Once one arrives in later life, differences in advantage or inequality are pronounced. For example, those with lower incomes earlier in adult life remain in positions of greater economic disadvantage throughout working life in contrast to those who begin in more lucrative occupations, where greater wealth and more resources are accrued and secured, through assets, savings, investments and private pensions (George, 2013; Crystal \& O'Shea, 1990). Lower socioeconomic status leads individuals to more likely become exposed to financial difficulties, stress, low job security, unhealthy habits and less physical activity (Seabrooke \& Avison, 2012). Cumulative inequality relates not only to income but also to culture, social class, education, housing, healthcare, transport and wider issues such as outmigration (Laceulle \& Baars, 2014; McGoey \& Goodfellow, 2008). Being female, widowed, living alone or in poor health all contribute to income inequality in later life (O'Rand, 1996), as in adulthood older women have lived through an economic system that minimises caring roles, excludes them from other opportunities (Rood-Wilson, 2010) and leads to their greater likelihood of having truncated and interrupted work patterns (O'Rand, 1996). What happens prior to retirement, therefore, is crucial to understand late disadvantage and difficulties experienced accessing social encounters when older (Walker, 2009). As such, studying the current condition and circumstances of an older person without regard for the accumulation of adverse life events is likely to prohibit the rigorous analysis of comparative loneliness (Ferraro \& Shippee, 2009). 
Table 2: Ferraro \& Shippee's (2009) Axioms of Cumulative Inequality

\begin{tabular}{ll}
\hline Axiom & \\
\hline One & Social systems generate inequality over the life course \\
Two & Disadvantage increases exposure to risk but advantage increases \\
Three & Trajectories are shaped by risk, resources and agency \\
Four & Perception of life trajectories influences subsequent trajectories \\
Five & Cumulative inequality may lead to premature mortality \\
\hline
\end{tabular}

\section{Social capital}

Social capital has been conceptualised as encompassing access to cooperative, trusted relationships and resources, civic engagement, and opportunities for reciprocity (Maass, Kloeckner, Lindstrøm, \& Lillefjell, 2016; Webber, Huxley \& Harris, 2011; Abbott, 2010; Lochner, Kawachi \& Kennedy, 1999). It relates to the ability to access benefits that help improve the living standards of an individual or community (Carillo Alvarez \& Riera Romani, 2017; Eriksson \& Ng, 2015; Putnam, 2000; Lochner et al., 1999; Portes, 1998). Social capital delivers social support, which buffers against negative stressors (Verheghe, Pattyn, Bracke, Verhaeghe \& Van De Putte, 2012) and allows the recipient to feel loved, cherished and valued (VillalongaOlives \& Kawachi, 2017). Feeling embedded in one's own neighbourhood increases a sense of social cohesion (Coll-Planas et al., 2017, Kleinhans, Priemus \& Engbersen, 2007) whilst being unable to access capital leads to exclusion (Daly \& Silver, 2008). Social capital has two further important subdivisions. Bonding capital usually comprises strong relationships with family, friends and neighbourhood contacts (Kadushin, 2012; Elgar et al., 2011) whilst bridging capital describes the links created with less familiar, but often more powerful, others outside the immediate social circle, which yield access to important resources (Elgar et al., 2011; Halpern, 2005; Putnam, 2000). Bridging capital, then, is particularly 
important in more impoverished neighbourhoods where access to external resources is especially valuable (Kim \& Cho, 2016).

Social networks may decrease with age (Forsman, Herberts, Nyqvist, Wahlbeck \& Schierenbeck, 2013) and older people become especially reliant on the capacity of their social connections and community resources in order to maintain a meaningful later life (Cagney $\&$ Wen, 2008). Continuing to access a wide range of social networks supports healthy ageing, gives a sense of belonging (Forsman et al., 2013; Litwin \& Shiovitz-Ezra, 2010) and can reduce depression symptomology (Haesda, Kondo, Takagi \& Kondo, 2018) but inability to access social capital may increase risk of depression (Webber et al., 2011). In later life, poorer health becomes a barrier for some to access adequate social capital (Nyqvist, Cattan, Andersson, Forsman \& Gustafson, 2013).

Both loneliness and cumulative inequality are relevant when considering individuals' social capital. Exchanging social support is protective against loneliness (Rodrigues, De Jong Gierveld \& Buz, 2014) and higher levels of loneliness predict lower levels of bonding or bridging social capital (Bian \& Leung, 2015). Accessing social capital successfully is impeded by lower socioeconomic status (Lager van Hoven \& Huigen, 2014), meaning the investigation of capital in the light of cumulative inequality is appropriate.

\section{Methods: Design and Procedure}

This article represents one aspect of a wider study on older people, loneliness and day centre programming. New attendees on 16-week well-being group work programmes at statutory day centres in Northern Ireland ( $\mathrm{NI}$ ) were invited to participate in a study investigating loneliness and group participation. Selected attendees kept diaries for the duration of their attendance and then were interviewed by the lead researcher about this, their experiences of loneliness and life histories. Two women, Amber and Rochelle, were part of this cohort. The stories constructed in this study derived from both submitted diaries and follow-up interviews. Whilst participants were asked to complete diaries on a weekly basis, both participants recorded entries daily throughout. The amount of recording completed 
is captured in Table 3. Interviews were conducted by the lead researcher with participants approximately three to four months following completion of group work to allow time for reflection.

Table 3: Diary Entries

\begin{tabular}{lll}
\hline Diarist & Number of diary entries & Total words \\
\hline Amber & 105 & 8,367 \\
Rochelle & 102 & 9,001 \\
\hline
\end{tabular}

Use of narrative

A narrative approach was chosen to both honour and preserve participant voice and perspective (Bohlmejer, Westerhof, Randall, Tromp \& Kenyon, 2011), and also apply the relevance of life history to current experiences. In narrative enquiry, participants determine what they believe to be relevant to the topic, selecting material to evaluate, understand, persuade, justify, engage and even misdirect (Frank, 2012; Reissman \& Quinney, 2005). Stories are constructed to ascribe meaning and emphasise connections and consequences (Phoenix, Smith \& Sparkes, 2010; Randall, 1999). Narrative enquiry allows older people to explore their longer lives, which are intense, complex and imbued with change (Phoenix et al., 2010; Randall, 1999), without losing the authorial voice (Reissman \& Quinney, 2005).

\section{Using diaries}

Dairies reveal what is contemporaneously important to writers, containing autobiographical reflections on choices, hopes and fears (Sheridan, 1993), highlighting their subjective innermost thoughts and feelings (Bartlett, 2011) and allowing space to make sense of a topic (Smith, 1999). As a research method, the diary is relatively unobtrusive (Furness \& Garrud, 2010), giving the respondent control over when and how much to write (Bartlett, 2011). In this study, the diary was solicited at the researchers' request. Whilst writing a solicited diary may result in a more structured, self-conscious recording aimed at a 
specific audience (Baldwin, 2015; Jacelon \& Imperio, 2005; Milligan, Bingley and Gatrell, 2005), the diarist maintains control over what to share or withhold and to record events not formally requested.

\section{Diary: diary-interview}

A biographical approach to exploring loneliness was chosen as the construct is not easily captured or explained by a 'snapshot' method (Bornat \& Bytheway, 2010). In this study, both diaries and interviews were used to elucidate perceptions of loneliness in light of respondents' current social interactions and their distinct histories. In the 'diary: diary-interview' model (Zimmerman \& Wieder, 1977), the diary acts as a "proxy observer" (Latham, 2003, p2001) in lieu of the researcher who cannot be ever present. Whilst events are sometimes forgotten during a retrospective interview (Milligan et al, 2005; Sheridan, 1993), diaries highlight significant moments (Latham, 2003; Zimmerman \& Wieder, 1977). Post diary interviews act as prompts to clarify selected diary entries (Bartlett, 2011), assist elaboration on a topic and check accuracy (Mackrill, 2007; Jacelon \& Imperio, 2005). In this study, pre-prepared questions, prompted by entries, were used, though the researcher aspired to a conversational approach, oriented towards the interviewee and what they wanted to say, rather than relying on questions alone (Fraser, 2004). For this study, whilst diaries commented mostly on present events, though Amber did reflect upon the origins and trauma of her son's brain injury, interviews were particularly useful in further exploring life histories and episodes that shed light on the participants' current situations. This meant that, during analysis, the impact of inequalities clearly emerged within both narratives.

\section{Sampling}

The two case examples were chosen from a larger sample of 91 day centre attendees, who completed questionnaires about loneliness and quality of life upon entry to therapeutic group programmes at various $\mathrm{NI}$ day centres, and also at programme end. Twelve individuals were selected from the 91 to complete diaries. Sampling was purposive as diarists/interviewees had to be those who felt sufficiently confident about completing the task and were interested in doing so. The criteria for choosing the two cases reported here were the opportunity they provided for in-depth analysis, the extensive nature of 
their data, their representativeness of the wider sample (in terms of age, gender and living arrangement) and the opportunity they provided to compare and contrast life experience.

When commencing their programme, the researcher gave prospective diarists a blank A5 book and information sheet, which included general instructions recommending writers reflect upon both the programme and their social lives outside the day centre, though respondents were encouraged to diverge in their entries from what had been requested (Mackrill, 2007). Diarists were asked to maintain entries for programme duration with the researcher retrieving journals during the final week. To avoid any coercion or intrusive direction, there was no further guidance given to allow diarists freedom in what and how they contributed. Allowing diarists a number of months permitted the writers to grow in confidence, become less self-conscious and elaborate on matters, which went far beyond those initially requested (Jacelon \& Imperio, 2005; Milligan et al, 2005). Finally, two participants were selected for narrative analysis to give prominence to and represent the individual storyteller voice, valuing the detailing of events as respondents experienced them and the language used to reflect upon these (Frank, 2012), and because of clear contrasts in cumulative inequalities. Diary entries were recorded onto NVivo software and a process of coding undertaken to determine categories and topics of interest. Subsequent interviews lasted roughly one hour. Interviews were semi-structured, with questions prompted by diary entries and experiences described by participants. Following this, the interviews were also transcribed via NVivo. At this point, the similarities within the two narratives chosen here appeared and an inductive reading of the data led to the emergence of cumulative inequality as a potential theoretical explanation of difference between the two accounts. This then informed the analytical approach of the article.

The researchers' challenge was to develop a story based on what was important to the storyteller (Hill \& Burrows, 2017; Reissman \& Quinney, 2005). The researchers engaged on a continuum between story analyst and storyteller (Phoenix et al., 2010) to create an accurate joint construction of meaning for the events outlined (de Meideros \& Rubinstein, 2015). Some long quotations have been used to respect the 
storyteller voice. The stories presented follow Frank's (2012) story framework with orienting information, followed by a complicating action and then some sense of resolution or evaluation.

Note on the text

All diary entries in the text below are reproduced as written with spelling and grammatical errors uncorrected. Ellipsis is used in both diary entries and interview transcripts to indicate a gap inserted by the researcher. Text omitted includes pauses, non-words and text that either seemed extraneous or required protection of identity. Any name cited is a pseudonym.

\section{Ethical Approval}

This study gained ethical approval from the NI Office for Research Ethics Committees (ORECNI; Ref 12/NI/0194). Each participant was provided with detailed written instructions regarding the research beforehand and gave written consent to their involvement.

\section{Findings}

\section{Two stories}

Amber and Rochelle have always lived in NI. Whilst Rochelle has mainly lived rurally throughout her life, Amber reports not just moving within urban and suburban locations but noting that these transitions were imposed upon her family.

Amber: We moved... into [current home] in 1975.... [T]hese were all just getting built, these houses... but when we moved down, this was all isolated. There was nobody and I said to my husband afterwards..., 'I'm not going to live there. There's nobody living near.'

When we lived in... [previous address], it was just starting the Troubles then. My... husband took a nervous breakdown 'cause there was a lot of trouble up in Belfast, shootings and 
things and ... I couldn't cope with it. And then when he came to [current location], he took a massive breakdown too.

By contrast, Rochelle's rural life was more settled. She lived with her husband in the same place throughout her marriage, a period of nearly sixty years. Although she took maternity leave, employment was steady and stable.

Rochelle: For the first seven years, well, I worked up until [daughter] was expected and... I decided to stop teaching then and, until after [second daughter] was born and she was over two, then I went back to teaching. Then I was in a little school down at [rural location]. It was a church school, belonging to the Presbyterian church and then a vacancy became vacant up in a little school, a two-teacher school... and I was there until I retired at... 58.

For Amber, one significant life event occurred that led to her becoming a full-time carer.

Amber: $\quad$ My son has bipolar disorder and has a head injury. He was in a car accident [in the late 1990s]... My son and [his friend] were in a car accident. It was very serious. They were both in intensive care.... [Friend]'s machine was switch off aged 18.... About 8 months after the accident I had to tell him about [friend]. He thought [friend] was still alive.... He screamed loudly and said I was telling lies. He came through a hard time and is still suffering after 16 years. Hasent worked since the accident, has a mentle illness. [Diary entry]

Amber's son's illness is an ongoing source of stress.

Amber: $\quad$ Sometimes he helps me but can't do a lot and my depression and panic... sets in. I shout a lot at him. I know it wrong but I need help in the house. He limited what he can do. 
I get very depressed.... I be in [local psychiatric hospital] worrying about my son. He put a strain on things. I know he can't help it all that what happened to him and losing his dad as well hasn't help. [Both diary entries]

Amber talked about the burden of this caring role in her interview and how attending a day centre programme temporarily alleviates this.

Amber: It's an escape for me when I go out... my door and go to this day centre. This is my wee time to myself. But when I go home and open my door, my problems... all... start up again.

Whilst Rochelle's son also sustained a head injury, the impact of this was not nearly so severe and her son lives independently.

Rochelle: [Son] developed epilepsy as the result of a bang on his head.... And his was so severe that he couldn't work and people didn't want to know him when he had epilepsy. But he's actually got it stabilised although he's still on his medication. And he's been allowed, allowed just this last year - it was 20 years since he'd been allowed to drive - so he's got a little car now, he can be allowed to drive because he's got stabilised.

Amber was supported in her caring role for her son by her husband and she now missed his input.

Amber: $\quad$ He must have talked to his daddy all about things. I'm sure he had his daddy's head away and... I didn't know that because... I'Il admit I'd be more close to my daughter.

However, Amber also recognised that her relationship with her husband could be troubled. 
Amber: $\quad$ He was a hard man to live with..., when he wasn't well but I coped.... People say to me I was a very strong willed woman.... Manys a time I was ready to run but I stuck by my husband for better, for worse, richer or poorer, sickness and in health, 'til death do us part.... My husband was that quiet of a man and then with him having his own problems with his breakdowns too, he used to say to me...., "Amber, I don't want hassle in my life." I says, “[husband], I know you don't want hassle, I know what you've come through and all but he needs the fatherly figure to tell him... right from wrong." He never smacked my son once and he never smacked my daughter.... I had to do the smacking of my son.

As well as struggling with mental ill-health, Amber recorded that her husband's death occurred following a period of poor physical health, with liver cancer and a tumour in his oesophagus. This loss is repeatedly evident in diary entries, recorded in the run up to the first anniversary of his death.

Amber: $\quad$ Lost my husband [last year]... on my son's birthday and his brother's anniversary. He died with cancer. It was in his liver.

I was married to my husband for 42 years.... I miss him so much.

Went to church. Had a mass said for my husband.... All the family were there. That was nice.... I said to myself I wasn't going to cry but I did. [Family members] went up to the grave. I went when my sister was home a few weeks earlier. I broke down and cried so I didn't go. [All diary entries]

Whilst Amber talks about her husband in 21 diary entries (including 12 occasions where she reflects on being anxious about his approaching anniversary), Rochelle mentions her husband only twice. 
Rochelle: In the afternoon my sister-in-law paid me a visit. It was so good to see her. She and I had a lovely time thinking back to past good times with our husbands, both of whom died in the spring of this year.

After the service... I went round to my husband's grave to place a holly wreath on it. [Both diary entries]

In her interview, Rochelle reflected on the post-work life she and her husband had enjoyed.

Rochelle: So I decided to retire then.... And... from then on [husband] and I had a very, very pleasant time. I mean, more than 20 years when we..., we didn't live a particularly, uh, fabulous life. We went mostly... we had a holiday in the summertime and then... during other times of the year, we would have gone out in the car... for little days out and things like that. But... when I retired, we decided to go off for the first time to the continent. We went to Yugoslavia..... It was amazing.

However, she did also reflect on some difficulties in the final years of her husband's life.

Rochelle: And then [husband] had a severe epileptic seizure and... maybe he had had a wee... stroke at the same time. So for the next... three years, I had people in.

Other family members play important roles for both women. Rochelle's other children have benefited from opportunities afforded by university education.

Rochelle: [daughter]... went to... the University... and she stayed there.... And then, [son]... first of all, he actually went to do some sort of science but he quickly realised it wasn't his cup of tea biology or something like that - and he changed over to doing art. 
Both women value the emotional support of their families.

Amber: I have seen my daughter and grandchildren.... They make me very happy and they cheer me up and they come around after school, stay for a few hours. [Diary entry]

Rochelle: Just about tea-time and my granddaughter came to see me. We had a lovely visit together: me telling her all about the holiday and she telling me about her new job. We had a cup of tea. [Diary entry]

Social support from families was particularly evident when it came to holidays. Amber spent time with her husband's brother's family in Ireland.

Amber: Went on holiday today down to my brother in law house for a week. The weather is great. Chilled out when we arrived.

Having a great time at [brother-in-law's]. [Brother-in-law's wife] looking after me and spoiling me. I mucking in, feeding chicken and planting lettuce.... Going to have a barbque tonight. [Both diary entries]

Rochelle availed of two family stays during her time recording. She spent Christmas with one son in England and on another occasion went to Spain with a daughter and her husband.

Rochelle: Arrived in Alicante about 10:10 am. Weather very sunny, temperature $28^{\circ} \mathrm{C} \ldots$... [Later] we went out to an Italian restaurant for dinner. Back to our apartment, $4^{\text {th }}$ floor duplex, with marvellous large balcony, views of sea, strand and mountain, on continuous sweep on three sides. Very beautiful. 
Absolutely a perfect Spanish summer day.... Beach packed. Went for swim .... Not nearly as good as I used to be, but I enjoyed it.... It's three years since I had my last swim in the 'Med'. [Both diary entries]

In terms of health, as well as being on anti-depressants, Amber recounted various physical health conditions that had been troubling her.

Amber: $\quad$ My health is not good myself. Had a heart condition. Have arthritis, crumbling bones in my neck. Have it in my knees, arm, back. Have been in hospital 3 times with pains in my chest but all the blood test were all right. [Diary entry]

Despite being nearly 17 years' older, Rochelle did not report any ongoing health conditions but did have occasional difficulties.

Rochelle: The only... thing that stands out... is I would be prone to migraines. Now I'm taking a daily tablet for migraine.

After coming home developed a nasty pain in my back, which got steadily worse. I think it was severe trapped wind. It caused me considerable discomfort.... Later a friend came in and the company helped to keep my mind off the pain. [Diary entry]

The lead researcher asked Rochelle about how company appeared to alleviate her low mood and if this could be linked to loneliness. 
Rochelle: Well, that would be... about maybe just feeling lonely or maybe if I'm not well and sort of don't want to do anything.... But yet, if there was anybody in the house, I would be away on my own. So it doesn't add up.

Rochelle reported how her social life was not disadvantaged by rural living.

Rochelle: Well, when I'm going to the craft morning, there are three other ladies. There's a man and his wife come and collect me and take me... When I would be going to the WI [Women's Institute], it's the WI lady that comes for me.... Once a month from the beginning of September there's the Presbyterian Women's Association meeting at the church and there's always somebody who'll come and take me there. There's no problem.

Whilst Rochelle reported not usually being lonely, Amber linked loneliness to the burden of caring for her son.

Amber: You know, there's an emptiness there but... [my husband] would want me to get on with my life and do good.... He was always the one who was out and about, I would have been the one who was sitting in the house all the time. I was the quiet one.... He used to shout at me, "Amber, you sit in the house too much. Get you out and go to places. Go to different places, you're a young woman.... Step out and go out instead of stuck in the house." Why I, I was stuck mostly in the house. 'Cause of my son. I didn't like leaving him.

Amber's experiences therefore may have led to social exclusion or a lack of social support. However, her diary also reveals that she maintains some social activities, including regular church attendance, involvement at a day centre and other informal craft groups. 
Amber: $\quad$ Going to my craft today and meeting my other friends. We talk and have tea. We do sewing, knitting and make all different things. I not long there but I enjoy it. [Diary entry]

As such, Amber's sense of loneliness is distinct from social isolation, and reveal a discrepancy between the social contact experienced and what she actually desires.

\section{Discussion}

As noted at the beginning of this article, research elsewhere has reported upon the impact of negative transitions in later life, such as bereavement and health declines, in promoting loneliness. These concerns are valid and important. However, the narratives here present a counterpoint to notions about loneliness, such as how those who live alone or in their 80 s may be lonelier, and indicating that, whilst individuals may experience similar events, such as spousal bereavement and brain injury to a son, other factors influence the impact of these traumatic incidents. By using cumulative inequality as a framework, the influence of the ecological systems surrounding the person, and in which they are embedded, cannot be ignored and the storytellers' tales inevitably embody interaction with their environment (Randall, Baldwin, McKenzie-Mohr, McKim \& Furlong, 2015; Laceulle \& Baars, 2014). This discussion now applies Ferraro \& Shippee's (2009) axioms of cumulative inequality, alongside reflections on social capital, to the above stories in order to evidence this.

One: Social systems generate inequality over the life course

Social capital is dependent upon the social and historical contexts in which individuals are located and, in NI, religious identity places an idiosyncratic and significant role (Daly \& Silver, 2008). Amber is a practising Catholic, with an early house relocation a direct result of the violence in Belfast in the early 1970s. This violence led to Catholics becoming more likely to leave the city (Gregory, Cunningham, Lloyd, Shuttleworth \& Ell, 2013) with an estimated 35,000 leaving homes due to intimidation (Shirlow \& Murtagh, 2006). Moreover, in NI, Catholic families were more likely to experience longer waiting times for social housing (Goeke-Morey et al., 2015). Residential segregation along religious lines is particularly 
marked in social housing (Murtagh, 2001), with estates often at least 90\% Catholic or Protestant (Horgan, 2011). Although Amber now owns her home, it is located in a social housing estate and was purchased under right to buy legislation. Her home is in an area ranked in the top $20 \%$ for multiple deprivations in $\mathrm{NI}$, including being in the top $10 \%$ for crime and disorder (NINIS/NISRA, 2017). News reports over the last couple of decades also reveal that Amber's estate has been associated with anti-social behaviour, substance misuse and dissident republicanism ${ }^{1}$. By contrast, Rochelle lives in an area ranked in the bottom third for multiple deprivation, including the bottom $10 \%$ for health deprivation, though her rural location ranks in the top $10 \%$ in terms of lacking access to services.

Additionally, secondary analysis of the NI Health and Wellbeing Survey in the late 1990s revealed that the Troubles probably had a significant impact on the population's mental health, and women who were widowed, in poor physical health and of low socioeconomic status were identified as being particularly vulnerable (O'Reilly \& Stevenson, 2003). Although her widowhood is comparatively recent, the impact of poor health and low socioeconomic status recurs in Amber's narrative. Whilst there is evidence of Amber receiving social support from family, strong bonds in impoverished areas are more likely to correlate with mental ill health, which itself is associated with less access to social capital generally (Hare Duke, 2017). Verhaeghe et al. (2011) hypothesise, following Portes' analysis, that working class bonds may have negative consequences regarding health behaviours due to working class communities having less access to resources. Additionally, on a structural level, the strong bonds apparent in poorer communities could deflect attention from the health, social and economic needs of these areas (Kim \& Cho, 2016; Lager et al., 2014; Keene, Bader \& Ailshire, 2013; Daly \& Silver, 2008), with an exaggerated sense that by 'pulling together', more deprived communities compensate for a lack of investment.

By contrast, Rochelle's rural location has been protective against the impact of the $\mathrm{NI}$ conflict and she has also been additionally advantaged by being part of the perceived socially dominant Protestant community (Levin, 2004). Owning her own home in a desirable area is a valuable asset for many older

\footnotetext{
${ }^{1}$ References with-held in order not to identify the specific location but can be made available upon request.
} 
people in later life (Forsman et al., 2013). As a former teacher with private pension provision, she is a member of the salariat (Goldthorpe, 2016), a class ranking associated with stronger social capital. Her children's access to third level education contrasts with Amber's family with associated resultant benefits of employment opportunities and financial reward (Baum, Ma \& Payea, 2013) giving Rochelle in her later years easier access to holidays abroad. Rochelle's rural location does not deprive her of a varied social network, including immediate neighbours and those living further afield. This echoes research findings that those living in rural neighbourhoods have better access to social capital, with a concomitant positive impact on self-rated health (Mohnen, Groenewegen, Volker \& Flap, 2011) and lower risk of depression (Webber, Huxley \& Harris, 2011).

Social capital is not immune to sectarianism (Daly \& Silver, 2008) and both Rochelle and Amber's location in communities that have developed structurally along religious lines consciously and subconsciously inform their ability to access different resources and opportunities. However, both reveal in their narratives a keen adherence to the spiritual dimensions of their faith. For women, religious faith buffers against loneliness (Lauder, Mummery \& Sharkey, 2006) and weekly church attendance maintains good mental health (Strawbridge, Shema, Cohen \& Kaplan, 2001) and allows social relationships to be forged and maintained (Wuthnow, 2002; Strawbridge et al., 2001). This may be especially and idiosyncratically so in $\mathrm{NI}$, where church affiliation and attendance is positively linked to the two dominant and distinct social identities, Protestantism and Catholicism, which help inform social comparisons, disadvantages and pathways to sectarianism (Goeke-Morey et al., 2015). Places of worship are shared spaces where a community maintain distinct norms and values (Kim \& Cho, 2016). Catholics particularly feel a strong sense of identity to their faith community, being almost ten times more likely to attend religious services regularly (Goeke-Morey et al., 2015) and more likely to report intra-community ties (Campbell, Hughes, Hewstone \& Cairns, 2008). Strong community bonds not only indicate who is included in a neighbourhood or social network but, also, importantly, who is excluded (Kleinhans et al., 2007), and in an NI context, this often relates to capital being divided along sectarian lines. Although Wuthnow (2002) argues that church attendance negotiates status bridging relationships, the idiosyncratic nature of NI may 
mitigate against this with Catholicism embodying a structural disadvantage in relation to the Presbyterianism to which Rochelle ascribes (Goeke-Morey et al., 2015). This reflects attitudes towards bridging social capital, which NI Catholic communities are both more likely to seek out and also be denied (Campbell et al., 2008).

Two: Disadvantage increases exposure to risk but advantage increases exposure to opportunity In these stories, the brain injury sustained by Amber's son places a much greater burden on her than a similar head injury, which led to epilepsy in Rochelle's son. In the mid/late 20th century, Rochelle could have been disadvantaged by being a woman suspending a career to take on motherhood and thus be relegated to lower paid employment (Joshi, Paci \& Waldfogel, 1999). However, her education was a protective factor (Goldthorpe, 2016) and Rochelle's professional qualification opened doors to further opportunities. Additionally, as a middle class Protestant woman, she was more likely to feel satisfied with her standard of living and access to opportunity as a member of a more privileged group (GoekeMorey et al., 2015). For Amber, the opportunity cost was much more severe and, as a working class woman, there would have been an expectation for her to be burdened with domestic roles (Gonzales de la Rocha, 2006). Her caring responsibilities coincided with a subsequent financial impact on the family, amplified by her husband's own ill health, a liability for higher household costs, less access to respite arrangements (Lynch \& Lyons, 2009) and lower social capital (Howard, 2001). Due to greater levels of engagement in informal networks, women are more likely to give and receive bonding capital whilst men build bridging social capital through career structures (Ferlander \& Makinen, 2009). The time committed to informal caring is hard to quantify or measure economically as it sometimes means being present, rather than carrying out an actual task (Himmelweit, 2007). However, the burden of 'having to be there' has an impact on reducing other opportunities, both economic and social (Ferlander \& Makinen, 2009) for Amber this relates to her reporting being so embedded in her home responsibilities that her husband urges her to go out. By contrast, increased access to social capital can lead to improvements in depression (Webber et al., 2011) and self-rated health (Verhaege et al., 2012). Maass et al. (2016) also found self-rated health to be related to socio-demographic variables that favoured those in higher 
classes. An additional contrast between Amber and Rochelle is that those who have chosen to retire report lower levels of loneliness than those who are out of work for other reasons (Lauder et al., 2006).

\section{Three: Trajectories are shaped by risk, resources and agency}

Informal networks developed prior to later life are essential capital to draw upon when older, though this is mediated through the neighbourhood or community in which one is based (Forsman et al., 2013). Length of residence leads to greater bonding social integration, particularly in poorer neighbourhoods (Keene et al., 2013), and a lack of bridging networks is also observed in lower-income neighbourhoods, with an associated impact on health (Kim \& Cho, 2016; Iwase et al., 2010). This is apparent in this study where, despite the two women's embeddedness in their locations, inequalities amplify their value in each case. Whilst one Irish study associates rural living with greater loneliness (Drennan et al., 2008), Rochelle did not feel lonely whilst Amber, living on the edge of town with her son, did. Despite the perceived association with loneliness, for longer term residents, rural living is accompanied by a stronger sense of belonging than in urban contexts (Young, Russell \& Powers, 2004). Household income is associated with higher levels of social capital (Kleinhans et al., 2007) and Rochelle's narrative reveals the wider resources she has to meet social needs, in terms of local groups, church life and holidays with family. Rochelle has community members she draws on for transport and her own diary reveals how she both visits and is visited by non-kin network members. This mix of social, cultural and economic capital is highly influential in promoting advantage (Savage et al., 2013). Whilst Amber also has access to social support and a cultural network, her agency is compromised by the intensity of her ongoing caring role, which impinges upon her physical and mental health. Even with access to social opportunities, relative impoverishment is associated with finding these social connections less beneficial than for those who have more resources and may even reinforce depressive symptomology (Haesda et al., 2018), or leave the individual feeling like they lack control or excluded from meaningful resources (Moore, Daniel, Gauvin \& Dube, 2009).

As individuals age, the resources in the immediate neighbourhood increase in value (Cagney \& Wen, 2008). Those with larger incomes and higher levels of education, such as Rochelle, are more likely to 
have wider friendship networks, be less vulnerable to loneliness (Litwin \& Shiovitz-Ezra, 2010), and have reduced stress and the psychological resources to deal with stressful episodes (Seabrooke \& Avison, 2012). By contrast, Amber's narrative reported a greater lack of receiving support from those beyond her immediate family with the relatively poor quality environment of the social housing estate in which she resided being unable to meet her social needs leading her to attend her church and social groups by foot, by public transport or from lifts from her daughter. Membership of these organisations may be less effective for stronger social capital than informal social contacts (Gray, 2009). Additionally, if her daughter were unavailable, she would struggle to afford travel costs to maintain social contacts and tasks outside her neighbourhood. It is not unusual in a deprived social housing estate for a resident's network to revolve moreso around family than regular interaction with neighbours (Verdouw \& Flanagan, 2019). However, widening the social network beyond family is important as friendships are an additional bolster to mental health in later life (Forsman et al., 2013). Social housing estates also can feel self-contained and thus marginalised and potentially disconnected from the wider urban environment that surrounds them (Scharf, Phillipson, Kingston \& Smith, 2001): this may be particularly so given the segregated nature of NI communities. Even accessing resources such as supermarket shopping can be difficult without a costly form of transport or flexible family members.

\section{Four: Perception of life trajectories influences subsequent trajectories}

The dispositions of both women are apparent in the narratives presented. In her diary, Amber makes repeated references to her bereavement and the emotional impact of this. Over 50 entries record her anxieties about her son and the associated stress and low moods. Even when she is outside the home, she continues to be plagued by thoughts about the potential discomfort she will return to when she comes home. By contrast, Rochelle is much more reticent to discuss feelings. Her recording style is more factual, presenting events with little reflection on negative emotion. Rochelle only cited feelings of loneliness when ill and feeling helpless. This may not be unusual. A sudden negative change of circumstance preying on one's state of mind was found when, following an earthquake in Christchurch, New Zealand, older people living alone were more likely to express feelings of loneliness (Wylie, 2012). 
The renowned and self-sufficient diarist May Sarton did not feel lonely when living alone, healthy and in control of her social life but, following her stroke, did so especially when sick or scared (Kane, 1999). It is when ill health strikes that the suitability of one's immediate environment for managing daily tasks comes under greater scrutiny. The diminished social control that chronic illness or disability brings may equate with greater loneliness.

\section{Five: Cumulative inequality may lead to premature mortality}

In their model, Ferraro \& Shippee (2009) note that, as analysis of those ageing increases into very old age, differences in inequality may minimise due to those who have experienced greater disadvantage being more likely to have died. Previous work has indicated that education and a larger income protect against mortality (Marmot, 2002) and those with low socioeconomic status and higher levels of loneliness are more likely to die earlier (Domenech-Abella et al., 2017). Income inequality and lower investment in social cohesion and capital in areas of poorer socioeconomic status are factors that lower life expectancy (Kawachi \& Kennedy, 1999), potentially resulting in a mortality difference of as much as $25 \%$ (Seabrooke \& Avison, 2012). In this study Amber, in her late 60s, cites multiple ailments, compared with Rochelle's relative stability. Additionally, Rochelle's husband died in very old age whilst Amber's was in his early sixties. As such, Amber experienced an uncommon loss (Currer, 2007), often accompanied by a more complicated grieving process, including further feelings of guilt, anger and issues being unresolved.

\section{Limitations}

Writing around cumulative inequality often emphasises the importance of both childhood events and how previous generations experienced advantage or disadvantage. One oversight in the interviews was that the participants' early lives was not covered. Therefore, the impact of events in adulthood has been the primary focus in this article. Rochelle's narrative and writing style is reflective of a middle class background and upbringing whilst Amber's appears to come from a working class background. However, how the individuals arrived in these socio-economic positions and, indeed, if they were explicitly there from childhood, has not been directly addressed. The researchers also recognise that the analytical 
approach is inevitably influenced by their own interpretations about what appears most important, which may not also accurately reflect the totality of the storyteller's meaning (Baldwin, 2015; Randall et al, 2015). Generally, as with much qualitative research, it may not be appropriate to apply the insights gleaned about the phenomena to a wider cohort (Reissman \& Quinney, 2005).

\section{Conclusion}

In summary, these participants' experiences of loneliness are mediated through life course inequalities, with social and cultural capital having a moderating effect. Both stories have revealed telling data about how these two women have accessed capital at both meso- and micro-levels (Carillo Alvarez \& Riera Romani, 2017), for example, in terms of how neighbourhood, work-life, church involvement and the immediate support of families enhance a sense of belongingness, but nuanced differences are also apparent. Whilst both women have strong bond connections with neighbourhoods and families, cumulative inequality amplifies Amber's sense of loneliness and low mood, in contrast to Rochelle receiving greater benefit from her network. Hers is a life that has comprised a rewarding career, a long retirement and broad support from a variety of family and friends. By being located in a lower status, social housing estate, and an area of greater deprivation, access to meaningful bridging resources has been more difficult for Amber (Kim \& Cho, 2016) and strong bonds in these areas are more likely to be associated with poorer health benefits (Verhaeghe \& Tampubolon, 2012). The application of cumulative inequality to the narratives presented here was valuable in reflecting how each individual's story is located within an ecology of other spheres of influence, including culture, resources and chance. Ferraro \& Shippee (2009)'s five axioms bear evidence that the impact of cumulative inequality in the lives of Amber and Rochelle has shaped both their social lives and amplified or diminished experiences of loneliness. Despite marked similarities in terms of two significant life events - bereavement and a son with a head injury - the impact of both events appears substantively more severe on the individual with less resources and capital, as the result of life events experienced in adulthood. Whilst both women access opportunities of social support, Amber's sense of loneliness is not resolved and rather is existentially linked to tragedy, trauma and a burden of care. There is a cognitive discrepancy between 
the social support she receives and that which would be sufficient in providing adequate comfort and respite. These women's stories reflect how their own life journeys have been determined by Bourdieu's (1977) concept of habitus, the arrangements into which they have been born, raised and lived their lives, or Giddens' structuration theory, where agency is constrained by the orchestrated structures and communities over which individuals have no control (Oppong, 2014). Both these explain the inevitable concomitant impacts on access to capital, opportunity, income and caring responsibilities. For example, whilst both women are mothers, only Amber experiences opportunity cost, revealing that there is greater vulnerability when considering the intersection between class and gender. Importantly, this article suggests that social capital should be viewed through the lens of cumulative inequality in order to determine not just the links, bonds and relationships that individuals have but the value of these in terms of ongoing benefits to health and greater resources in later life. A link between material disadvantage and loneliness has been made elsewhere (McGoey \& Goodfellow, 2008). This article both supports this and also identifies a range of further advantages and disadvantages in individual life journeys that should not be underestimated when considering vulnerability to loneliness.

One final footnote. One further observation is that, whilst Amber and Rochelle are divided along class and religious lines, both attended the same day centre, revealing that statutory services have the capacity to break down these barriers and provide a bridge to social mixing that does not usually otherwise transpire in these women's social lives.

\section{References}

Abbott, S. (2010). Social capital and health: The role of participation. Social Theory \& Health, 8(1), 5165.

Adams, K. B. Sanders, S. \& Auth, E. A. (2004). Loneliness and depression in independent living retirement communities: Risk and resilience factors, Aging \& Mental Health, 8(6), 475-485. 
Baldwin, C. (2015). Narrative ethics for narrative care. Journal of Aging Studies, 34, 183-189, doi: 10.1016/j.jaging.2015.02.014.

Bartlett, R. (2011). Using diaries in research with people with dementia (Realities toolkit 18). Manchester: University of Manchester.

Baum, S., Ma, J. \& Payea, K. (2013). Education pays 2013: The benefits of higher education for individuals and society. New York: College Board Trends in Education Series.

Baumeister, R. F. \& Leary, M. R. (1995). The need to belong: Desire for interpersonal attachments as a fundamental human motivation. Psychological Bulletin, 117(3), 497-529.

Bian M \& Leung L (2015) Linking loneliness, shyness, smartphone addiction symptoms, and patterns of smartphone use to social capital. Social Science Computer Review, 33(1), 61-79.

Bohlmeijer, E. T., Westerhof, G. J., Randall, W., Tromp, T. \& Kenyon, G. (2011). Narrative foreclosure in later life: Preliminary considerations for a new sensitizing concept. Journal of Aging Studies, 25, 364-370, doi: 10.1016/j.jaging.2011.01.003.

Bornat, J. and Bytheway, B. (2010). Perceptions and presentations of living with everyday risk in later life. British Journal of Social Work, 40, 1118-1134, doi: 10.1093/bjsw/bcq001.

Bourdieu, P. (1977). Outline of a theory in practice (2013 printing). Cambridge: Cambridge University press.

Burholt, V. \& Scharf, T. (2014). Poor health and loneliness in later life: The role of depressive symptoms, social resources and rural environments. Journal of Gerontology, Series B; Psychological Sciences \& Social Sciences 69(2), 311-324, doi: 10.1093/geronb/gbt121.

Cagney, K. A. \& Wen, M. (2008). Social capital and aging-related outcomes. In Kawachi, I.m Subramanian, S. V. \& Kim, D. (eds.). Social capital and health. New York: Springer Verlag, 239258.

Caiels, J., Forder, J., Malley, J., Netten, A. \& Windle, K. (2010). Measuring the outcomes of low-level services: Final report. Canterbury: Personal Social Services Research Unit discussion paper 2699. Campbell, A., Hughes, J., Hewstone, M., \& Cairns, E. (2010). Social capital as a mechanism for building a sustainable society in Northern Ireland. Community Development Journal, 45(1), 22-38. 
Carrillo Álvarez, E., \& Riera Romaní, J. (2017). Measuring social capital: Further insights. Gaceta Sanitaria, 31, 57-61.

Coll-Planas, L., del Valle Gomez, G., Bonilla, P., Masat, T., Puig, T., \& Monteserin, R. (2017). Promoting social capital to alleviate loneliness and improve health among older people in S pain. Health \& social care in the community, 25(1), 145-157.

Currer, C. (2007). Loss and social work. Exeter: Learning Matters.

Crystal, S. \& Shea, D. G. (1990). Cumulative advantage, cumulative disadvantage, and inequality among elderly people. The Gerontologist, 30(4): 437-443, doi: 10.1093/geront/30.4.437

Daly, M., \& Silver, H. (2008). Social exclusion and social capital: A comparison and critique. Theory and society, 37(6), 537-566.

Dannefer,D. (2003) Cumulative advantage/ and disadvantage and the life course: cross fertilising age and social science theory. Journal of Gerontology, Psychological Sciences and Social Sciences, 58, S327-37.

Dannefer, D., \& Settersten, R. A. (2010). The study of the life course: Implications for social gerontology. In Dannefer, D. \& Phillipson, C. (Eds.). The SAGE handbook of social gerontology. London: Sage, 319.

De Jong Gierveld, J., Dykstra, P. A., \& Schenk, N. (2012). Living arrangements, intergenerational support types and older adult loneliness in Eastern and Western Europe. Demographic Research, 27, 167, doi: 10.4054/DemRes.2012.27.7.

De Jong Gierveld, J. \& Van Tilburg, T. (1999). Manual of the loneliness scale. Amsterdam: Department of Social Research Methodology.

Domènech-Abella, J., Mundó, J., Lara, E., Moneta, M. V., Haro, J. M., \& Olaya, B. (2017). The role of socio-economic status and neighborhood social capital on loneliness among older adults: evidence from the Sant Boi Aging Study. Social psychiatry and psychiatric epidemiology, 52(10), $1237-1246$. 
Drennan, J., Treacy, M., Butler, M., Byrne, A., Fealy, G., Frazer, K. \& Irving, K. (2008). The experience of social and emotional loneliness among older people in Ireland. Ageing and Society, 28, 11131132, doi: 10.1017/S0144686X08007526.

Dykstra, P. A., Van Tilburg, T. G., \& Gierveld, J. D. J. (2005). Changes in older adult loneliness: Results from a seven-year longitudinal study. Research on aging, 27(6), 725-747; doi: 10.1177/0164027505279712.

Elgar, F. J., Davis, C. G., Wohl, M. J., Trites, S. J., Zelenski, J. M and Martin, M. S. (2011). Social capital, health and life satisfaction in 50 countries. Health and Place, 17, 1044-1053.

Eriksson, M., \& Ng, N. (2015). Changes in access to structural social capital and its influence on selfrated health over time for middle-aged men and women: A longitudinal study from northern Sweden. Social Science \& Medicine, 130, 250-258.

Ferlander, S., \& Mäkinen, I. H. (2009). Social capital, gender and self-rated health. Evidence from the Moscow Health Survey 2004. Social Science \& Medicine, 69(9), 1323-1332.

Ferraro, K. F. \& Shippee, T. P. (2009). Aging and cumulative inequality: How does inequality get under the skin? The Gerontologist, 49(3), 333-343; doi: 10.1093/geront/gnp034.

Forsman, A. K., Herberts, C., Nyqvist, F., Wahlbeck, K., \& Schierenbeck, I. (2013). Understanding the role of social capital for mental wellbeing among older adults. Ageing \& Society, 33(5), 804-825.

Frank, A. W. (2012). Practicing dialogical narrative analysis. Varieties of narrative analysis, 33-52; doi: 10.4135/9781506335117.n3.

Fraser, H. (2004). Doing narrative research: Analysing personal stories line by line. Qualitative Social Work, 3(2), 179-201; doi: 10.1177/1473325004043383.

Fried, E.I., Bockting, C., Arjadi, R., Borsboom, D., Amshoff, M., Cramer, A.O., Epskamp, S., Tuerlinckx, F., Carr, D. \& Stroebe, M. (2015). From loss to loneliness: The relationship between bereavement and depressive symptoms. Journal of abnormal psychology, 124(2), 256-265; doi: 10.1037/abn0000028.

Furness, P. J. and Garrud, P. (2010). Adaptation after facial surgery: Using the diary as a research tool. Qualitative Health Research, 20, 2, 262-272; doi: 10.1177/1049732309357571. 
Gaugler, J. E. \& Zarit, S. H. (2001). The effectiveness of adult day services for disabled older people. Journal of Aging and Social Policy, 12(2), 23-47.

George, L. K. (2013). Age structures, aging, and the life course. In Wilmoth, J. M. \& Ferraro, K. F. (Eds.). Gerontology: Perspectives and issues. New York: Spencer Publishing Company, 149-172.

Goeke-Morey, M. C., Cairns, E., Taylor, L. K., Merrilees, C. E., Shirlow, P., \& Cummings, E. M. (2015). Predictors of strength of in-group identity in Northern Ireland: Impact of past sectarian conflict, relative deprivation, and church attendance. Journal of community \& applied social psychology, 25(4), 283-295.

Goldthorpe, J. H. (2016). Social class mobility in modern Britain: Changing structure, constant process. Journal of the British Academy, 4, 89-111.

Gonzalez de la Rocha, M. (2006). Vanishing assets: Cumulative disadvantage among the urban poor. Annals of the American Academy, 606, doi: 10.1177/002716206288779.

Gray, A. (2009). The social capital of older people. Ageing and Society, 29(1), 5-31.

Gregory, I. N., Cunningham, N. A., Lloyd, C. D., Shuttleworth, I. G. \& Ell, P. S. (2013). Troubled geographies: A spatial history of religion and society in Ireland. Bloomington, Indiana: Indiana University Press.

Haesda, M., Kondo, N., Takagi, D. and Kondo, K. (2018). Community social capital and inequality in depressive symptoms among Japanese adults: A multilevel study. Health and Place, 52, 8-17.

Halpern, D. (2005). Social capital. Cambridge: Polity Press.

Hare Duke, L. (2017). The importance of social ties in mental health. Mental Health and Social Inclusion, 21(5), 264-270.

Heinrich, L. M. \& Gullone, E. (2006). The clinical significance of loneliness: A literature review. Clinical Psychology Review, 26, 695-718.

Hill, C. \& Burrows, G. (2017). New voices: The usefulness of a narrative approach to social work research. Qualitative Social Work, 16(3), 273-288; doi: 10.1177/1473325017689966.

Himmelweit, S. (2007). The prospects for caring: Economic and policy analysis. Cambridge Journal of Economics, 31, 581-599; doi: 10.1093/cje/bem011. 
Horgan, G. (2011). The making of an outsider: Growing up in poverty in Northern Ireland. Youth \& Society, 43(2), 453-467.

Howard, M. (2001). Paying the price: Carers, poverty and social exclusion. London: Child Poverty Action Group/Carers UK.

Iwase, T., Suzuki, E., Fujiwara, T., Takao, S., Doi, H., \& Kawachi, I. (2012). Do bonding and bridging social capital have differential effects on self-rated health? A community based study in Japan. Journal of Epidemiology and Community Health, 66(6), 557-562.

Jacelon, C. S. and Imperio, K. (2005). Participant diaries as a source of data in research with older adults. Qualitative Health Research, 15, 7, 991-997; doi: 10.1177/1049732305278603.

Joshi, H., Paci, P. \& Waldfogel, J. (1999). The wages of motherhood: Better or worse. Cambridge Journal of Economics, 23(5), 542-564; doi: 10.1093/cje/23.5.543.

Kadushin, C. (2012). Understanding social networks: Theories, concepts and findings. Oxford: Oxford University Press.

Kane, R. A. (1999). Goals of home care: Therapeutic, compensatory, either, or both? Journal of Aging \& Health, 11, 3, 299-321; doi: 10.1177/089826439901100303.

Keene, D., Bader, M., \& Ailshire, J. (2013). Length of residence and social integration: The contingent effects of neighborhood poverty. Health \& place, 21, 171-178.

Kawachi, I., \& Kennedy, B. P. (1999). Income inequality and health: pathways and mechanisms. Health services research, 34(1), 215-227.

Kim, C. O., \& Cho, B. H. (2016). Can geographic bridging social capital improve the health of people who live in deprived urban neighborhoods?. International Journal of Health Services, 46(4), 767-789.

Kleinhans, R., Priemus, H., \& Engbersen, G. (2007). Understanding social capital in recently restructured urban neighbourhoods: two case studies in Rotterdam. Urban studies, 44(5-6), 1069-1091.

Laceulle, H., \& Baars, J. (2014). Self-realization and cultural narratives about later life. Journal of aging studies, 31, 34-44.

Lager, D., Van Hoven, B., \& Huigen, P. P. (2015). Understanding older adults' social capital in place: Obstacles to and opportunities for social contacts in the neighbourhood. Geoforum, 59, 87-97. 
Latham, A. (2003). Research, performance, and doing human geography: Some reflections on the diaryphotograph, diary-interview method. Environment and Planning A, 35, 1993-2017; doi: $10.1068 / a 3587$.

Lauder, W., Mummery, K., \& Sharkey, S. (2006). Social capital, age and religiosity in people who are Ionely. Journal of Clinical Nursing, 15(3), 334-340.

Levin, S. (2004). Perceived group status differences and the effects of gender, ethnicity, and religion on social dominance orientation. Political Psychology, 25(1), 31-48.

Litwin, H., \& Shiovitz-Ezra, S. (2010). Social network type and subjective well-being in a national sample of older Americans. The Gerontologist, 51(3), 379-388.

Lochner, K., Kawachi, I. and Kennedy, B. P. (1999). Social capital: A guide to its measurement. Health and Place, 5, 259-270.

Lynch, K. \& Lyons, M. (2009). Gender, social class and lone caring: The intersectionality of inequalities. In Lynch, K., Baker, J. \& Lyons, M. (eds.). Affective equality: Love, care and injustice. Basingstoke: Palgrave Macmillan, 93-113.

Maass, R., Kloeckner, C. A., Lindstrøm, B., \& Lillefjell, M. (2016). The impact of neighborhood social capital on life satisfaction and self-rated health: A possible pathway for health promotion?. Health \& Place, 42, 120-128.

Mackrill, T. (2007). Using a cross-contextual qualitative diary design to explore client experiences of psychotherapy. Counselling \& Psychotherapy Research: Linking research with practice, 7, 4, 233 239; doi: 10.1080/14733140701722455.

Marmot, M. (2002). The influence of income on health: Views of an epidemiologist. Health Affairs, 21(2), 31-46.

McGoey, M. \& Goodfellow, M. (2008). Cumulative disadvantage and elderly need for services: A phenomenological inquiry. Journal of Rural Community Psychology, E10(2).

Milligan, C., Bingley, A. and Gatrell, A. (2005). Digging deep: Using diary techniques to explore the place of health and well-being amongst older people. Social Science and Medicine, 61, 1882-1892; doi: 10.1016/j.socscimed.2005.04.002. 
Mohnen, S. M., Groenewegen, P. P., Volker, B. \& Flap, H. (2011). Neighborhood social capital and individual health. Social Science and Medicine 72, 660-667.

Moore, S., Daniel, M., Gauvin, L. and Dube, L. (2009). Not all social capital is good capital. Health and Place, 15, 1071-1077.

Murtagh, B. (2001). Integrated social housing in Northern Ireland. Housing Studies, 16(6), 771-789.

NINIS/NISRA (2017). NI Multiple Deprivation Measure 2017. Retrieved 25 October 2019 from http://www.ninis2.nisra.gov.uk/InteractiveMaps/Deprivation/Deprivation\%202017/SOA Depriva tion Map/atlas.html

Nyqvist, F., Cattan, M., Andersson, L., Forsman, A. K., \& Gustafson, Y. (2013). Social capital and loneliness among the very old living at home and in institutional settings: A comparative study. Journal of aging and health, 25(6), 1013-1035.

Oppong, S. (2014). Between Bandura and Giddens: structuration theory in social psychological research? Psychological Thought, 7(2), 111-123.

O'Rand, A. (1996). The precious and the precocious: Understanding cumulative disadvantage and advantage over the life course. The Gerontologist, 34(2), 230-238; doi: 10.1093/geront/36.2.230.

O'Reilly, D. \& Stevenson, M. (2003). Mental health in Northern Ireland: Have 'the Troubles' made it worse? Journal of Epidemiological Community Health 57, 488-492; doi: 10.1136/jech.57.7.488.

Phoenix, C., Smith, B.. \& Sparkes, A. C. (2010). Narrative analysis in aging studies: A typology for consideration. Journal of Aging Studies, 24, 1-11; doi: 10.1016/j.jaging.2008.06.003.

Portes, A. (1998). Social capital: Its origins and applications in modern sociology. Annual Review of Sociology, 24, 1-24.

Putnam, R. D. (2000). Bowling alone: The collapse and revival of American community. London: Simon \& Schuster.

Randall, W. L. (1999). Narrative intelligence and the novelty of our lives. Journal of Aging Studies, 13(1), 11-28; doi: 10.1016/S0890-4065(99)80003-6. 
Randall, W. L., Baldwin, C., McKenzie-Mohr, S., McKim, E. \& Furlong, D. (2015). Narrative and resilience: A comparative analysis of how older adults story their lives. Journal of Aging Studies, 34, 155161; doi: 10.1016/j.jaging.2015.02.010.

Reissman, C. K. \& Quinney, L. (2005). Narrative in social work: A critical review. Qualitative Social Work, 4(4), 391-412; doi: 10.1177/1473325005058643.

Rood-Wilson, C. (2010). Aging Michiganders: Demographic changes and cumulative inequality. Michigan Sociological Review,74-96.

Rodrigues, M. M. S., De Jong Gierveld, J., \& Buz, J. (2014). Loneliness and the exchange of social support among older adults in Spain and the Netherlands. Ageing \& Society, 34(2), 330-354; doi: 10.1017/S0144686X12000839.

Russell, D. W., Cutrona, C. E., McRae, C. \& Gomez, M. (2012). Is loneliness the same as being alone? The Journal of Psychology: Interdisciplinary \& Applied, 146 1-2), 7-22.

Savage, M., Devine, F., Cunningham, N., Taylor, M., Li, Y., Hjellbrekke, J.,Le Roux, B., Friedman, S. \& Miles, A. (2013). A new model of social class? Findings from the BBC's Great British Class Survey experiment. Sociology, 47(2), 219-250; doi: 10.1177/0038038513481128.

Scharf, T., Phillipson, C., Kingston, P., \& Smith, A. E. (2001). Social exclusion and older people: exploring the connections. Education and Ageing, 16(3), 303-320.

Seabrook, J. A., \& Avison, W. R. (2012). Socioeconomic status and cumulative disadvantage processes across the life course: implications for health outcomes. Canadian Review of Sociology/Revue canadienne de sociologie, 49(1), 50-68.

Sheridan, D. (1993). Writing to the archive: Mass-observation as autobiography. Sociology, 27, 1, 27-40; doi: $10.1177 / 003803859302700104$.

Shirlow, P. \& Murtagh, B. (2006). Belfast: Segregation, violence and they city. London: Pluto Press. Smith, J. A. (1999). Identity development during the transition to motherhood: An interpretative phenomenological analysis. Journal of Reproductive and Infant Psychology, 17(3), 281-299; doi: 10.1080/02646839908404595. 
Strawbridge, W. J., Shema, S. J., Cohen, R. D., \& Kaplan, G. A. (2001). Religious attendance increases survival by improving and maintaining good health behaviors, mental health, and social relationships. Annals of Behavioral Medicine, 23(1), 68-74.

Verdouw, J., \& Flanagan, K. (2019). 'I call it the dark side': Stigma, social capital and social networks in a disadvantaged neighbourhood. Urban Studies, 0042098018817226.

Verhaeghe, P-P., Pattyn, E., Bracke, P., Verhaeghe, M. and Van De Putte, B. (2012). The association between network social capital and self-rated health: Pouring old wine in new bottles? Health and Place, 18, 358-365.

Verhaeghe, P. P., \& Tampubolon, G. (2012). Individual social capital, neighbourhood deprivation, and self-rated health in England. Social science \& medicine, 75(2), 349-357.

Victor, C. R. and Bowling, A. (2012). A longitudinal analysis of loneliness among older people in Great Britain. The Journal of Psychology: Interdisciplinary and Applied, 146, 3, 313-331; doi: 10.1080/00223980.2011.609572.

Villalonga-Olives, E. \& Kawachi, I. (2017). The dark side of social capital: A systematic review of the negative effects of social capital. Social Science and Medicine, 194, 105-127.

Walker, A. (2009). Why is age so unequal? In McCann, P. \& Dean, M. (Eds.). Unequal ageing: The untold story of exclusion in old age. Bristol: Policy Press, 141-158.

Webber, M., Huxley, P. and Harris, T. (2011). Social capital and the course of depression: six-month prospective cohort study. Journal of Affective Disorders, 129, 1-3, 149-157.

Wuthnow, R. (2002). Religious involvement and status-bridging social capital. Journal for the scientific study of religion, 41(4), 669-684.

Wylie, S. (2012). Social isolation and older people in Canterbury. Canterbury: Age Concern Canterbury.

Young, A. F., Russell, A., \& Powers, J. R. (2004). The sense of belonging to a neighbourhood: can it be measured and is it related to health and well being in older women?. Social Science \& Medicine, 59(12), 2627-2637.

Zimmerman, D. H. and Wieder, D. L. (1977). The diary: diary-interview method. Urban Life, 5, 4, 479498; doi: 10.1177/089124167700500406. 